\title{
THE EFFECTS OF GOSSIP ON INTERPERSONAL TRUST DEPEND ON PROSOCIALITY OF THE GOSSIPERS
}

\author{
KONRAD RUDNICKI ${ }^{*}{ }^{1}$, CHARLOTTE DE BACKER ${ }^{1}$, and CAROLYN DECLERCK ${ }^{2}$ \\ *Corresponding Author: konrad.rudnicki@uantwerpen.be \\ ${ }^{1}$ Department of Communication Science, University of Antwerp, Antwerp, Belgium \\ ${ }^{2}$ Department of Management, University of Antwerp, Antwerp, Belgium
}

\section{Evolutionary roots of gossip}

Gossip is broadly defined as an evaluative information exchange about third parties (Foster, 2004). In 1998 Robin Dunbar developed a theory that gossip as a method of social grooming allowed humans to significantly expand their social group size (Dunbar, 1998). More specifically, gossip was proposed to boost ingroup trust. That idea was supported by studies showing that interpersonal gossip indeed promotes in-group cooperation (Boero et al., 2009; Feinberg et al., 2012; Piazza \& Bering, 2008; Sommerfeld et al., 2008). Meanwhile, another theory was coined, that modern mass media are able to trigger mechanisms that evolved to deal with issues of interpersonal communication (Barkow, 1989). Because a modern subset of gossip - celebrity gossip, is a relatively new phenomenon it is not yet known if it is able to trigger the same effects as interpersonal gossip, and would its effects differ between face-to-face and online communication. This study is designed to test if celebrity gossip can enhance trust, just like interpersonal gossip does.

\subsection{Prosociality}

The social grooming theory of language states that gossip enables people to exchange information about the wrongdoings of others and punish the free-riders that exploit the group (Dunbar, 1998). Therefore, gossip can have a different effect on people depending on their attitude towards group living, since it protects those acting prosocially and threatens those who tend to be pro-self oriented. It was shown that prosocial individuals are intrinsically motivated to cooperate, and 
the main determinants of trust for them are extraneous social cues signaling the trustworthiness of their interaction partner (Bogaert et al., 2008). Gossip is rich in social information and might create transparency by revealing reputation information about others. It has been shown that prosocially oriented people use reputation gossip concerning the wrongdoings of others to warn about potential free-riders (Feinberg et al., 2012). Therefore, we hypothesize that celebrity gossip will increase trust of prosocial individuals $\left(\mathbf{H}_{1}\right)$. Conversely, proselfs do not seek trust signals but situations with ambiguous social information that offer more opportunities to exploit others (Boone et al., 2010). Therefore, we hypothesize that celebrity gossip will decrease trust of proself individuals $\left(\mathrm{H}_{2}\right)$.

\section{Methods}

A $2 \times 2 \times 2$ experimental design was used. Participants either gossiped about celebrities or performed a creativity task. Both tasks were performed either faceto-face or online with audio, but without video. Additionally, participants were classified as either prosocial or proself, based on Social Value Orientation questionnaire results (Van Lange et al., 1997). Trust was determined using an investment game with strategy method (detailed procedure in: Berg et al., 1995). 114 females participated in the experiment $\left(M_{a g e}=21.96\right)$.

\section{Results}

Because participants interacted, the data was clustered by pairs of participants and analyzed as panel data in linear regression (Table 1).

Table 1. Regression model.

\begin{tabular}{|c|c|}
\hline & $\beta$ \\
\hline Gossip & $-2.8(1.8)$ \\
\hline Anonymity & $-0.9(2.1)$ \\
\hline Prosociality & $-0.8(1.5)$ \\
\hline GossipXAnonymity & $0.1(2.4)$ \\
\hline GossipXProsociality & $3.9(1.9)$ \\
\hline AnonymityXPros. & $0.2(1.9)$ \\
\hline Goss.XAnon.XPros. & $0.2(2.4)$ \\
\hline Wald chi ${ }^{2}$ & $20.2^{* *}$ \\
\hline
\end{tabular}

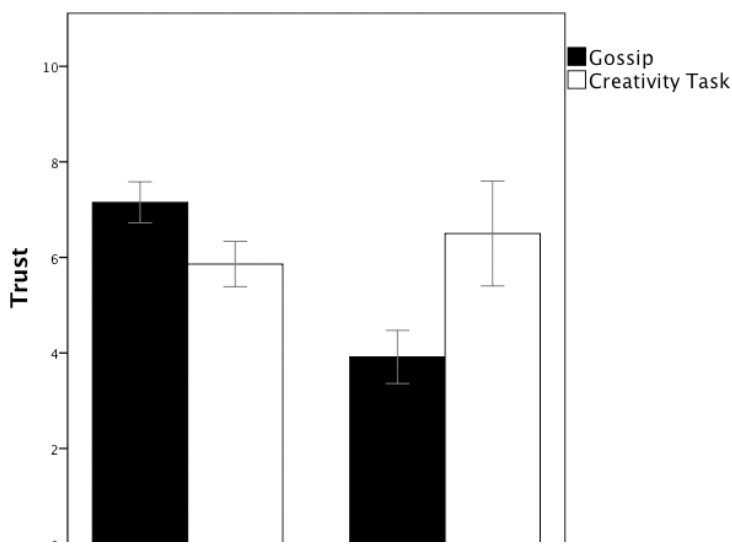

Figure 1. The impact of gossip on trust for prosocials and proselfs. 


\section{Conclusion}

In line with our hypotheses prosocials trusted their interaction partner more, whereas proselfs trusted their partner less after gossiping about celebrities. This provides support for the idea that gossip serves as an evoutionary mechanism to maintain the in-group cohesion which partially corroborates of the social grooming theory of language evolution (Dunbar, 1998). The fact that even modern celebrity gossip can have such an effect plays into the narrative that modern mass media are also able to trigger evolutionary mechanisms of interpersonal communication (Barkow, 1989). At the same time, the effect observed in our study was strictly dependent on social value orientation of the gossipers, which highlights how important it is to remember that evolutionary mechanisms can also be affected by individual differences (Nettle, 2007).

\section{References}

Berg, J., Dickhaut, J., \& McCabe, K. (1995). Trust, reciprocity, and social history. Games and economic behavior, 10(1), 122-142.

Boero, R., Bravo, G., Castellani, M., \& Squazzoni, F. (2009). Reputational cues in repeated trust games. The Journal of Socio-Economics, 38(6), 871-877.

Bogaert, S., Boone, C., \& Declerck, C. (2008). Social value orientation and cooperation in social dilemmas: A review and conceptual model. British Journal of Social Psychology, 47(3), 453-480.

Boone, C., Declerck, C., \& Kiyonari, T. (2010). Inducing cooperative behavior among proselfs versus prosocials: the moderating role of incentives and trust. Journal of Conflict Resolution, 54(5), 799-824.

Dunbar, R., \& Dunbar, R. I. M. (1998). Grooming, gossip, and the evolution of language. Harvard University Press.

Feinberg, M., Willer, R., Stellar, J., \& Keltner, D. (2012). The virtues of gossip: Reputational information sharing as prosocial behavior. Journal of Personality and Social Psychology, 102(5), 1015-1030.

Nettle, D. (2007). Individual differences. In R. I. M. Dunbar \& L. Barrett (Eds.), Oxford handbook of evolutionary psychology (pp. 479 - 489). Oxford, UK: Oxford University Press.

Piazza, J., \& Bering, J. M. (2008). Concerns about reputation via gossip promote generous allocations in an economic game. Evolution and Human Behavior, 29(3), 172-178.

Sommerfeld, R. D., Krambeck, H. J., \& Milinski, M. (2008). Multiple gossip statements and their effect on reputation and trustworthiness. Proceedings of the Royal Society of London B: Biological Sciences, 275(1650), 2529-2536.

Van Lange, P. A., De Bruin, E., Otten, W., \& Joireman, J. A. (1997). Development of prosocial, individualistic, and competitive orientations: theory and preliminary evidence. Journal of Personality and Social psychology, 73(4), 733-746. 